\title{
Thermogravimetric Assessment of Combustion Characteristics of Blends of Lignite Coals with Coal Gangue
}

\author{
Chang-Zhong SONGa ${ }^{a}$, Jiang-Hui WEN, Yu-Yin LI, Hong DAN, Xin-Ying SHI, \\ Shen XIN
}

\author{
Inner Mongolia University of Technology, School of energy and power engineering, \\ Inner Mongolia, Hohhot, China \\ asongchzh@imut.edu.cn
}

Keywords: Lignite, Coal, Combustion characteristics.

\begin{abstract}
In this paper, the co-combustion behaviour of lignite coal with coal gangue and coal are investigated by a thermogravimetric analysis (TGA) in the temperature range from ambient temperature to $1000{ }^{\circ} \mathrm{C}$. The thermal characteristics and kinetics of lignite coal, coal gangue and their blends are evaluated under combustion conditions using a non-isothermal thermogravimetric method (TGA). Lignite coal is blended with coal gangue in the range of 25-75 wt. \% to evaluate their cocombustion behaviour. Such attempts of Combustion characteristics index under different proportions of analysis may help to identify appropriate blend proportion for a given coal gangue and to derive some specific advantages with respect to particular combustion practice.
\end{abstract}

\section{Introduction}

The energy demand of the world is continuously increasing in parallel with population increase and industrial development [1-2]. This demand has been met by fossil fuels particularly from coal until now. Coal gangue is composed of various minerals and accretes with coal stratum [3-6].Its dominant minerals are quartz and silicate layered clay minerals. Currently, it is one of the largest emissions of industrial solid waste.

The characteristics of low calorific and limitations of the prior art combustion value fuel, which limit its large-scale use [7], but mixed combustion is an effective way to improve their combustion and combustion efficiency [8-10]. The mechanism of low calorific value of blended coal combustion was understood by the study of lignite coals and coal gangue mixed combustion dynamics, which can effectively guide the combustion process. There are many methods of the combustion process. This study that researches methods in combination with coal combustion characteristics by thermal analysis techniques, can provide strongly theoretical support for stabilizing the low calorific value fuel combustion, and offer energy use and low calorific value boiler burning some guidance significance [11-14].

\section{Experimental}

\section{Materials}

The experimental material of coal gangue was collected from Ximeng city of Inner Mongolia Province in China. The lignite coal was obtained from Erdos city of Inner Mongolia Province in China. The materials' proximate analyses are shown in Table 1. The initial coal sample was milled and sieved into less than $741 \mathrm{~m}$ in diameter. The coal gangue sample was milled and sieved in less than $2001 \mathrm{~m}$. The lignite coal sample was milled and sieved into less than $2001 \mathrm{~m}$. Finally, lignite coal was mixed with coal gangue and lignite coal in the proportion of 25, 40, 60 and75 (wt. \%) in the fuel blend. The materials were stored in the laboratory under dry conditions.

The mixture of lignite coal and coal gangue was determined in a SETARAM thermo- gravimetric analyzer. The combustible mass of the samples was kept at $10 \mathrm{mg}$. In the air flux of $30 \mathrm{~mL} \cdot \mathrm{min}^{-1}$, the furnace temperature was increased from ambient temperature to $1000{ }^{\circ} \mathrm{C}$ at the speed of $10 \mathrm{~K} \cdot \mathrm{min}^{-}$ 
${ }^{1}$. The weight of sample was monitored continuously as a function of temperature. The TG, DTG and DTA experiment of lignite coal, coal gangue and the mixed fuel were completed.

Table 1. Analysis parameter of coal

\begin{tabular}{|c|c|c|c|c|c|}
\hline & $\mathrm{M}_{\mathrm{ad}}$ & $\mathrm{A}_{\mathrm{ad}}$ & $\mathrm{V}_{\mathrm{ad}}$ & $\mathrm{F}_{\mathrm{cad}}$ & $\mathrm{V}_{\text {daf }}$ \\
\hline lignite coal & 16.85 & 9.98 & 37 & 46.18 & 44.48 \\
\hline lignite coal : coal gangue $=4: 1$ & 15.70 & 24.30 & 33.24 & 36.76 & 45.46 \\
\hline lignite coal : coal gangue $=3: 2$ & 9.59 & 31.52 & 27.30 & 31.59 & 46.36 \\
\hline lignite coal : coal gangue $=2: 3$ & 6.74 & 44.39 & 24.10 & 24.77 & 49.31 \\
\hline lignite coal : coal gangue $=1: 4$ & 3.23 & 50.29 & 18.47 & 16.88 & 52.30 \\
\hline coal gangue & 1.56 & 69.32 & 16.99 & 12.13 & 58.34 \\
\hline
\end{tabular}

Table 2. Characteristic temperature of the sample

\begin{tabular}{|c|c|c|c|c|}
\hline sample & $\mathrm{T}_{\mathrm{i}}$ & $\mathrm{Tmax}_{\mathrm{max}}$ & $\mathrm{T}_{\mathrm{f}}$ & $(d w / d t)_{\max }$ \\
\hline lignite coal & 336 & 422 & 603 & 2.8696 \\
\hline lignite coal : coal gangue $=4: 1$ & 366 & 501 & 611 & 2.3179 \\
\hline lignite coal : coal gangue $=3: 2$ & 355 & 508 & 579 & 2.3865 \\
\hline lignite coal : coal gangue $=2: 3$ & 400 & 519 & 577 & 2.3275 \\
\hline lignite coal : coal gangue $=1: 4$ & 435 & 520 & 565 & 2.1408 \\
\hline coal gangue & 444 & 520 & 577 & 2.5713 \\
\hline
\end{tabular}

Table 3. Characteristics of the sample index

\begin{tabular}{|c|c|c|c|c|c|}
\hline sample & $\mathrm{D}_{\mathrm{i}} / /^{-5}$ & $C / 10^{-5}$ & $\mathrm{H}_{\mathrm{F}}$ & $\mathrm{C}_{\mathrm{b}}$ & $\mathrm{S} / 10^{-8}$ \\
\hline lignite coal & 1.41 & 2.5363 & 1.9129 & 0.0022 & 3.9431 \\
\hline lignite coal : coal gangue $=4: 1$ & 1.03 & 1.7241 & 2.3349 & 0.0042 & 4.0214 \\
\hline lignite coal : coal gangue $=3: 2$ & 1.16 & 1.8927 & 2.3072 & 0.0052 & 5.3402 \\
\hline lignite coal : coal gangue $=2: 3$ & 1.01 & 1.4547 & 2.2479 & 0.0048 & 3.8804 \\
\hline lignite coal : coal gangue $=1: 4$ & 0.869 & 1.1314 & 2.1353 & 0.0041 & 2.7239 \\
\hline coal gangue & 1.00 & 1.3017 & 2.0518 & 0.0033 & 1.9330 \\
\hline
\end{tabular}

\section{Effects of Blend Proportion on Combustion Process}

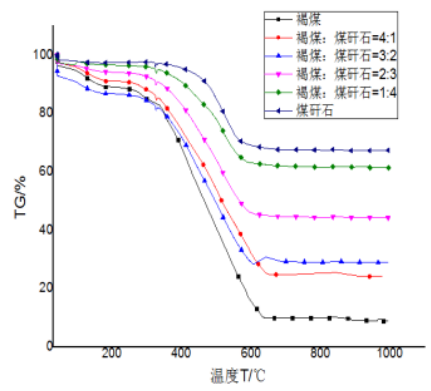

(a)

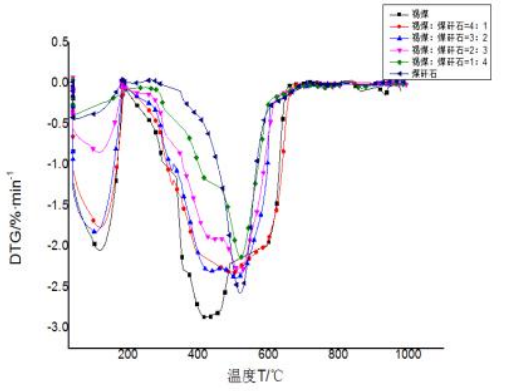

(b)

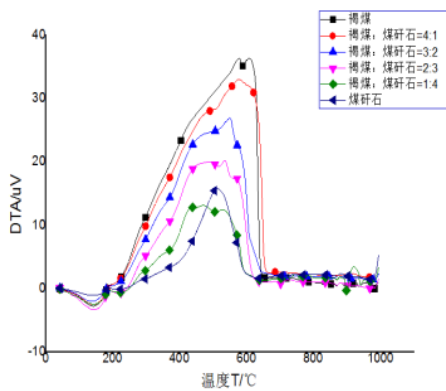

(c)

Fig. 1. Combustion profiles of the blends

The co-burning profiles of different blends have been compared with the profiles of high ash coal gangue and high moisture lignite coal. As shown in Fig. 1(a), with the increase in the proportion of lignite coal, coal samples enhance the rate of weight loss. With the increase in the proportion of lignite coal, coal samples in turn enhance the rate of weight loss, the higher the ratio of lignite is, and the greater the loss of weight is. As shown in Fig. 1(b), combustion process can be divided into three stages for interpret. The temperature range of the first stage is from ambient temperature at the 
beginning of the test to about $200^{\circ} \mathrm{C}$. This phase can be obtained from the DTA endothermic curve, corresponding to a loss of moisture. The second stage begins at $200^{\circ} \mathrm{C}$ and ends in about $600{ }^{\circ} \mathrm{C}$. This stage exothermic reaction can be obtained from the DTA curve, which includes the devolatilization, volatile combustion and combustion of fixed carbon [15]. The third stage begins at $600^{\circ} \mathrm{C}$ and ends in $1000{ }^{\circ} \mathrm{C}$. In this stage, the weight loss of the samples were very slight. With the lignite coal increasing, the residue yield of the samples decreases.

In the first stage and second stage, the maximum value of DTG curves of the samples increases with lignite coal increasing. Because the first stage is moisture precipitation, the high moisture content of lignite can be obtained from the table1. In the second stage, when lignite content is higher than $50 \%$ in the mixture, the curve were similar, and there are clearly two peak points; when the gangue content is higher than $50 \%$ in the mixture, there are clearly a peak point. Due to the fixed carbon combustion is associated with the degree of coal rank, the higher the coal rank is, the more carbon content is, and ignition temperature of fixed carbon is higher. By devolatile and combustion to reach ignition temperature to be fixed carbon combustion. Low coal rank coal gangue has less volatile content, but a higher degree of coalification of lignite has the large volatile content. From Fig 1. (b), the mixture of coal gangue content of greater than $50 \%$ is saw. The devolatilization and combustion peak is barely small and the fixed carbon combustion has a larger weightlessness peak; in the mixture, when the proportion of lignite content is higher than 50\%, devolatilization and combustion's weightlessness loss peak is large and the weightlessness loss peak of the fixed carbon combustion is small. When considering devolatilization, combustion characteristics and combustion of fixed carbon, lignite accounted for $60 \%$ of the blend of combustion characteristics is the best, which may be due to their synergies [16-20].

Results from thermogravimetry analysis for lignite coal and coal gangue blend under different proportion. Combustion characteristic temperature table 2 obtained from Fig. 1.

As indicated in Table 2, with coal gangue increasing, $\mathrm{T}_{\mathrm{i}}$ increases and $\mathrm{T}_{\mathrm{f}}$ decreases. Maximum DTG tends to decrease. The coal gangue content in the sample decreases, which means that reactions are slower, if lignite coal is lower.

\section{Combustion Characteristics Index under Different Proportions of Analysis}

The following parameters characterize the combustion characteristics of Table 3 can be obtained from Table 2.

\section{Ignition Index $D_{\mathrm{i}}$ is Determined by the Equation as Follows:}

$$
D_{i}=\frac{D T G_{\max }}{T_{i} \times T_{f}}
$$

Where DTG $_{\max }$ is the maximum combustion rate. $\mathrm{T}_{\mathrm{i}}$ is the corresponding temperature of the ignition and $T_{f}$ is the corresponding temperature of the burnout. The larger the ignition index is, the better the performance of the ignition is. With the proportion of lignite increasing, the fire index increases. Mixed coal, lignite ignition index maximum amount of $60 \%$, the proportion of mixed coal ignition is the best performance.

Flammability Index $\mathrm{C}$ is Determined by the Equation as Follows:

$$
C=\frac{(d w / d t)_{\max }}{T_{i}^{2}}
$$

where $((\mathrm{dw}) /(\mathrm{dt}))_{\max }$ is the maximum combustion rate. $T_{i}$ is the corresponding temperature of the ignition. Flammability index indicates TG curve trends from ignition point to the maximum rate of weightlessness loss point of this range may be characterized by the stability of the combustion ignition flammability index. The larger the flammability index is, the better the coal's combustibility is. With the lignite increasing, the flammability index increases. Mixed coal, lignite flammability index maximum amount of $60 \%$, the proportion of mixed coal flammability is the best performance. 


\section{Combustion Stability Index HF is Determined by the Equation as Follows:}

$$
H_{F}=T \max \ln \left(\frac{\mathrm{DT}}{\mathrm{DTG}_{\max }}\right) 10^{-3}
$$

$\mathrm{T}_{\max }$ is the maximum combustion rate corresponding temperature. DT has exothermic peak width. DTG $_{\max }$ is the maximum value of DTG. HF is largely considered to characterize coal combustion rate after coal combustion speed and intensity of the ignition and burn performance and capable of reacting after coal ignition combustion stability. $\mathrm{H}_{\mathrm{F}}$ is smaller, the performance of coal combustion is better. With the lignite increasing, combustion stability index increasing, mixed coal combustion is more stable than a single coal.

\section{Burnout Characteristics Index CB is Determined by the Equation as Follows:}

$$
\begin{gathered}
C_{b}=\frac{f 1 * f 2}{\tau_{0}} \\
f_{1}=\left(m_{0}-m_{1}\right) /\left(m_{0}-m_{e}\right) \\
f_{2}=\left(m_{0}-m_{2}\right) /\left(m_{0}-m_{e}\right)
\end{gathered}
$$

$f_{1}$ is the ignition point of combustible coal sample weight loss ratio quality content and coal, the initial burn rate; $\mathrm{f}_{2}$ is the post burnout rate; $\tau_{0}$ is the burn time. $\mathrm{Cb}_{b}$ combines the influence factors of coal combustion stability and burnout on fire, the greater its value, the combustion performance is the better. With the lignite increasing, combustion burnout index increases. Mixed coal combustion is more complete than a single coal, especially lignite burnout index maximum amount of $60 \%$, the proportion of mixed coal burnout is the best performance. Mixed coal's burnout characteristics are better than a single coal.

Comprehensive Behavior of Combustion Index $S$ is Determined by the Equation as Follows:

$$
S=\frac{(d w / d \tau)_{\max } \times(d w / d \tau)_{\text {mean }}}{T_{i}^{2} \times T_{f}}
$$

$(d w / d \tau)_{\max }$ is the maximum combustion rate, $(d w / d \tau)_{\text {mean }}$ is the average burn rate,$T_{i}$ is the corresponding temperature of the ignition. $T_{f}$ is the corresponding temperature of the burnout. Combustion characteristics index $\mathrm{S}$ is an integrated coal ignition and burnout characteristic index. The higher value of $S$ indicates the better combustion characteristics of coal samples. With the lignite increasing, combustion characteristics index increases. Lignite combustion characteristics index maximum amount of $60 \%$, the proportion of mixed coal ignition is the best performance. Comprehensive blended coal combustion performance is better than a single sample of coal.

\section{Conclusions}

The text showed the effects of blend proportion on combustion process and combustion characteristics index under different proportions of analysis. The appropriate blend proportion for a given coal gangue was $60 \%$ from the experiment .Several comprehensible differences mainly resulted from the rank differences of the materials of high ash coal gangue and high volatile lignite coal. Due to the fixed carbon combustion with coal rank, the higher the coal rank was, the more carbon content was, and ignition temperature of fixed carbon was higher. The mixed coal of the burnout characteristics v combustion stability and comprehensive behavior of combustion was better than a single coal. This study had some practical significance. 


\section{Acknowledgment}

This paper is supported by Project funding: National Natural Science Foundation Project (Project ID: 51466010).

\section{References}

[1] Marisamy Muthuraman. Characteristics of co-combustion and kinetic study on hydrothermally treated municipal solid waste with different rank coals: A thermogravimetric analysis [J], Applied Energy, 2010, 87: 141-148.

[2] Li Xiang-guo. Thermogravimetric analysis of the co-combustion of theblends with high ash coal and waste tyres [J], Thermochimica Acta, 2006, 441: 79-83.

[3] M. Varol. Investigation of co-combustion characteristics of low quality lignite coals andbiomass with thermogravimetric analysis [J], Thermochimica Acta, 2010, 510: 195-201.

[4] M. Otero. Co-combustion of different sewage sludge and coal: A non-isothermal thermogravimetric kinetic analysis [J], Bioresource Technology, 2008, 99: 6311-6319.

[5] M. Varol. Investigation of co-combustion characteristics of low quality lignite coals and biomass with thermogravimetric analysis [J], Thermochimica Acta, 2010, 510: 195-201.

[6] Marisamy Muthuraman. Characteristics of co-combustion and kinetic study on hydrothermally treated municipal solid waste with different rank coals: A thermogravimetric analysis [J], Applied Energy, 2010, 87: 141-148.

[7] Xiao Hanmin. Co-combustion kinetics of sewage sludge with coal and coal gangue under different atmospheres [J], Energy Conversion and Management, 2010, 51: 1976-1980.

[8] Li Xiang-guo. Thermogravimetric analysis of the co-combustion of the blends with high ash coal and waste tyres [J], Thermochimica Acta, 2006, 441: 79-83.

[9] S.G. Sahu. Thermogravimetric assessment of combustion characteristics of blends of a coal with different biomass chars [J], Fuel Processing Technology, 2010, 91: 369-378.

[10] X.G. Li. Thermogravimetric investigation on co-combustion characteristics of tobacco residue and high-ash anthracite coal [J], Bioresource Technology, 2011, 102: 9783-9787.

[11] Zhengang Liu. Thermogravimetric investigation of hydrochar-lignite co-combustion [J], Bioresource Technology, 2012, 123: 646-652.

[12] X.G. Li. Thermogravimetric investigation on co-combustion characteristics of tobacco residue and high-ash anthracite coal [J], Bioresource Technology, 2011, 102: 9783-9787.

[13] Li Xiang-guo. Thermogravimetric analysis of the co-combustion of the blends with high ash coal and waste tyres [J], Thermochimica Acta, 2006, 441: 70-83.

[14] Liao Yanfen. Thermogravimetric analysis of the co-combustion of coal and paper mill sludge [J], Applied Energy, 2010, 87: 3526-3532.

[15] M. Oteroa,b. Co-combustion of different sewage sludge and coal: A non-isothermal thermogravimetric kinetic analysis [J], Bioresource Technology ,2008, 99: 6311—6319.

[16] Xiao Hanmin. Co-combustion kinetics of sewage sludge with coal and coal gangue under different atmospheres [J], Energy Conversion and Management, 2010, 51: 1976-1980.

[17] S.G. Sahua. Thermogravimetric assessment of combustion characteristics of blends of a coal with different biomass chars [J], Fuel Processing Technology, 2010, 91: 369-378.

[18] M.V. Gil. Thermal behaviour and kinetics of coal/biomass blends during co-combustion [J], 
Bioresource Technology, 2010, 101: 5601-5608.

[19] M. Varol a. Investigation of co-combustion characteristics of low quality lignite coals and biomass with thermogravimetric analysis [J], Thermochimica Acta, 2010, 510: 195-201.

[20] Zhengang Liu. Thermogravimetric investigation of hydrochar-lignite co-combustion [J], Bioresource Technology, 2012, 123: 646-652. 